\title{
Recobrimento de laranja 'Pêra' com filme de concentrado protéico de soro de leite associado a plastificantes
}

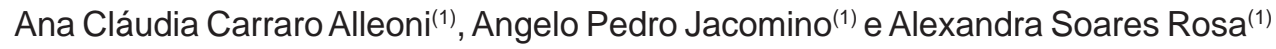

(1)Escola Superior de Agricultura Luiz de Queiroz, Dep. de Produção Vegetal, Av. Pádua Dias, 11, Caixa Postal 09,
CEP 13418-900 Piracicaba, SP. E-mail: anaccarraro@terra.com.br, jacomino@esalq.usp.br, srosa@esalq.usp.br

Resumo - O objetivo desse estudo foi avaliar o efeito de coberturas à base de concentrado protéico de soro de leite (CPSL), associadas a dois tipos de plastificantes (glicerol e sorbitol), em laranja 'Pêra'. As frutas foram lavadas e higienizadas de acordo com os padrões comerciais e submetidas à aplicação das coberturas. As coberturas à base de CPSL não foram eficientes na redução da perda de massa fresca da laranja 'Pera', independentemente do plastificante utilizado. Depois de 11 dias de armazenagem, as laranjas cobertas com solução filmogênica de 6\% de proteína e 6\% de glicerol, e laranjas cobertas com solução de 4\% de proteína e 8\% de sorbitol perderam menos massa, quando comparadas às outras combinações de proteína e plastificante. As coberturas não interferiram nas características físico-químicas das laranjas.

Termos para indexação: Citrus sinensis, cobertura comestível, glicerol, sorbitol, permeabilidade ao vapor d’água.

\section{'Pêra' orange coating with whey protein concentrate film associated to plasticizers}

\begin{abstract}
The objective of this work was to evaluate the effect of whey protein coating plasticized with glycerol and sorbitol in 'Pêra' oranges. Fruits were washed and sanitized, according to trade pattern, and then coated. Whey protein coatings was not effective in avoiding oranges weight reduction, independently of plasticizing. After 11 days of storage, the oranges coated with 6\% protein and 6\% glycerol, and with $4 \%$ protein and $8 \%$ sorbitol, lost less weight than other treatments. Coating did not modify physico-chemical characteristics of the oranges.
\end{abstract}

Index terms: Citrus sinensis, edible coating, glycerol, sorbitol, water vapour permeability.

\section{Introdução}

Filmes chamados comestíveis têm recebido atenção nos últimos anos, principalmente em razão de seu potencial de aplicação em alimentos. Os filmes constituem barreiras à perda de vapor d'água e à troca gasosa, além de serem materiais de embalagens biodegradáveis (Shaw et al., 2002).

Coberturas com biopolímeros, como carboidratos, lipídios e proteínas, têm sido utilizadas para modificar as atmosferas internas de frutas e vegetais (CisnerosZevallos \& Krochta, 2003). Lipídios e ceras são usados em coberturas para reduzir a permeabilidade ao vapor d'água, por serem hidrofóbicos e apolares, o que possibilita a formação de boas barreiras para a migração da umidade (Krochta, 2002). A cera de carnaúba é regularmente utilizada em emulsões, mas não é uma barreira efetiva na prevenção de perda d'água, $\mathrm{O}_{2}, \mathrm{CO}_{2}$ e etileno (Mota et al., 2003).
As coberturas à base de proteínas destacam-se por serem comestíveis, biodegradáveis e promoverem boa barreira contra gás. Formam também uma proteção mecânica, o que aumenta a vida pós-colheita e minimiza a deterioração do alimento (Cho et al., 2002).

A formação de filmes provenientes de hidrocolóides necessita de um biopolímero, para promover a matriz estrutural, e de um plastificante de baixo peso molecular, para aumentar a flexibilidade do filme (Shaw et al., 2002). Plastificante é uma substância não-volátil que, quando adicionada a um material altera suas propriedades mecânicas e/ou físicas. O sorbitol e o glicerol são plastificantes por suas habilidades em reduzir as pontes de hidrogênio, enquanto aumentam os espaços intermoleculares, e em diminuir as interações entre as cadeias de polímeros, aumentando a flexibilidade e diminuindo as propriedades de barreiras dos filmes (Banker, 1966). 
Thomazine et al. (2005) observaram que com o aumento na concentração de plastificante (glicerol e sorbitol), em filmes de gelatina, ocorre aumento da permeabilidade ao vapor d'água e da flexibilidade do filme.

As proteínas do soro de leite, quando processadas apropriadamente, produzem filmes flexíveis, transparentes e sem odores (Gennadios et al., 1994). Alleoni \& Antunes (2004) observaram menor perda de massa em ovos cobertos com concentrado protéico de soro de leite. Os filmes de proteínas de soro de leite, armazenados em ambientes com alta umidade relativa, apresentam alta permeabilidade ao oxigênio (Cisneros-Zevallos \& Krochta, 2002). A permeabilidade ao vapor d'água desses filmes está mais relacionada com as quantidades de glicerol e com a concentração de íon de cálcio do que com a concentração de proteínas (Fang et al., 2002). Baixas quantidades de plastificantes tornam quebradiços os filmes de proteínas de soro de leite (Talens \& Krochta, 2005).

Nos frutos não climatéricos, como é o caso dos citros, a respiração diminui durante o amadurecimento, e as transformações bioquímicas que tornam o fruto maduro ocorrem de forma mais lenta. O amadurecimento só ocorre se o fruto estiver aderido à planta, diferentemente do que ocorre nos frutos climatéricos, que amadurecem mesmo após a colheita (Wills et al., 1998). Durante o processo de amadurecimento, a perda progressiva da firmeza do fruto é resultado da perda de vapor d'água e de uma transformação gradual da protopectina para a pectina, a qual é degradada pela enzima poligalacturonase na parede celular (Park, 1999). Essa degradação da pectina é atribuída à grande difusão de gases através dos tecidos do fruto (Park, 1999).

Os filmes protéicos vêm sendo empregados há muito tempo para conservação dos alimentos (Donhowe \& Fennema, 1994). Entretanto, há poucos relatos do uso deste revestimento, com diferentes tipos de plastificantes, aplicados diretamente às frutas. $\mathrm{O}$ desenvolvimento de recobrimentos alternativos, com matérias-primas abundantes, é desejável, para aumentar o período de armazenamento de frutas, a fim de manter a qualidade e estender a vida útil do produto.

Considerando-se que o Brasil é o maior produtor mundial de frutas cítricas (Agrianual, 2002), e que a variedade Pêra é uma das mais cultivadas, utilizada tanto na indústria de suco concentrado quanto no mercado de frutas in natura, torna-se importante o estudo de novas alternativas para armazenamento de citros.
Nesse estudo, avaliaram-se os efeitos de coberturas à base de concentrado protéico de soro de leite, associadas a dois tipos de plastificantes, glicerol e sorbitol, nas características físicas e químicas da laranja 'Pêra', durante a armazenagem.

\section{Material e Métodos}

Foram utilizadas laranjas (Citrus sinensis) da variedade Pêra, fornecida por empresas da região de Limeira, SP, que beneficiam frutas cítricas para os mercados interno e externo.

Foram utilizados lotes homogêneos de frutas sem defeitos ou danos. As laranjas foram lavadas e higienizadas de acordo com padrões comerciais, sem aplicação de ceras. Após a sanitização, os frutos foram submetidos à aplicação das coberturas. As determinações foram feitas com cinco repetições de cada tratamento. Foram empregadas soluções filmogênicas, que continham 4, 6 ou 8\% de proteína de concentrado protéico de soro de leite (CPSL) (matriz estrutural), associado a 3 e $6 \%$ de glicerol como plastificante (experimento 1); e 4 e $8 \%$ de sorbitol como plastificante (experimento 2). Os experimentos foram realizados com lotes diferentes de frutas. A concentração de sorbitol foi maior do que a de glicerol nas soluções filmogênicas, a fim de que os filmes apresentassem resistência mecânica semelhante (McHugh \& Krochta, 1994).

Os delineamentos experimentais foram inteiramente casualizados, em esquema fatorial 3x2 (concentração de proteína $\mathrm{x}$ concentração de plastificante), com seis tratamentos, além do controle (sem cobertura).

O concentrado protéico de soro de leite utilizado para produzir as coberturas foi o Calpro 8002. A solução de cobertura foi preparada da seguinte maneira: o concentrado foi dissolvido em água e, depois de completada a dissolução da proteína, foi acrescentado o plastificante, e o volume foi completado com água (p/p). Quando necessário, o pH da solução foi ajustado para 7 com $\mathrm{NaOH} 1 \mathrm{~mol} \mathrm{~L}^{-1}$, pois a menor permeabilidade ao vapor d'água ocorre com pH 7, em soluções filmogênicas de proteínas do soro de leite (Pèrez-Gago \& Krochta, 1999). Em seguida, as soluções foram aquecidas a $90 \pm 1^{\circ} \mathrm{C}$, por 30 minutos, e depois resfriadas até $25^{\circ} \mathrm{C}$.

As frutas foram imersas nas soluções de CPSL à temperatura próxima de $25^{\circ} \mathrm{C}$; após a imersão, foram colocadas em prateleiras metálicas, numa câmara a $22 \pm 1^{\circ} \mathrm{C}$ e umidade relativa de $80 \pm 2 \%$. Depois de 24 horas, foi realizada a primeira pesagem das frutas e 
a avaliação da cor da casca, correspondentes ao dia 1. A seguir, foram realizados os cálculos de perda de massa e análises de cor da casca dos frutos após 3, 5, 7, 9 e 11 dias. As determinações físico-químicas foram realizadas no dia em que as laranjas chegaram no laboratório e no final dos experimentos.

A perda de massa foi calculada pela diferença entre a massa inicial (dia 1) e a final (dias 3, 5, 7, 9 e 11) dos frutos pesados em balança semi-analítica, com os resultados expressos em porcentagem.

A cor da casca foi determinada com colorímetro Minolta CR-300. Foram realizadas quatro leituras, em lados opostos, na região de maior diâmetro do fruto. Os resultados foram expressos em ângulo de cor $\left({ }^{\circ} \mathrm{h}\right)$, considerando-se a média das leituras.

O teor de sólidos solúveis totais (SST) foi determinado por refratômetro digital Atago PR-101, e os resultados foram expressos em ${ }^{\circ}$ Brix.

A acidez titulável (ATT) foi determinada pela diluição de $10 \mathrm{~g}$ do suco em $90 \mathrm{~mL}$ de água destilada, e a titulação foi feita com hidróxido de sódio $\left(0,1 \mathrm{~mol} \mathrm{~L}^{-1}\right)$ até a solução atingir $\mathrm{pH}$ 8,1 (ponto de viragem da fenolftaleína), os cálculos foram realizados segundo Carvalho et al. (1990), e os resultados expressos em gramas de ácido cítrico por $100 \mathrm{~g}$ de suco.

Os rendimentos do suco foram calculados com base na fórmula: rendimento $(\%)$ = massa do suco x 100/massa da fruta.

Para perda de massa, o delineamento experimental foi inteiramente casualizado, em um esquema fatorial $3 \times 2 \times 5$, em que os fatores foram as concentra- ções de proteínas, as concentrações de plastificantes e os períodos de armazenamento (3, 5, 7, 9 e 11 dias).

Para cor da casca, o esquema foi o descrito acima, com exceção dos períodos de armazenamento, nos quais foi incluído o dia 1 . As comparações de médias, dentro de cada período de armazenamento, foi feita pelo teste de Tukey $(\mathrm{p}<0,05)$.

\section{Resultados e Discussão}

Na análise estatística dos resultados do experimento 1, ocorreu interação tripla entre concentração de proteína, concentração de glicerol e período de armazenamento $(\mathrm{p}<0,01)$. Assim, foi feito o desdobramento desses fatores. Observou-se que a perda de massa aumentou com o tempo de armazenamento, independentemente das concentrações de proteína e de glicerol (Tabela 1).

O glicerol é considerado bom plastificante, em termos de tecnologia de filmes e coberturas comestíveis. Entretanto, é muito sensível à umidade relativa do ambiente, pois permite a migração de moléculas de água para fora do filme (Thomazine et al., 2005). Essa perda de massa das frutas cobertas pode estar relacionada com a alta umidade relativa utilizada (80\%). De acordo com Cisneros-Zevallos \& Krochta (2003), a permeabilidade do filme hidrofílico aumenta com o aumento da umidade relativa do ambiente. A perda de massa de $2 \%$, neste estudo, depois de cinco dias de armazenamento, foi semelhante à obtida em maçã Fuji por Cisneros-Zevallos \& Krochta (2003), após quatro dias de armazenamento, à mesma temperatura e $90 \%$ de UR.

Tabela 1. Perda porcentual de massa de laranja 'Pera' coberta com concentrado protéico de soro de leite e plastificantes (glicerol e sorbitol) durante o período de armazenamento.

\begin{tabular}{|c|c|c|c|c|c|c|c|}
\hline \multirow[t]{2}{*}{ Tratamentos } & \multirow{2}{*}{$\begin{array}{c}\text { Plastificante } \\
(\%)\end{array}$} & \multirow{2}{*}{$\begin{array}{c}\text { Proteína } \\
(\%)\end{array}$} & \multicolumn{5}{|c|}{ Período de armazenamento (dias) } \\
\hline & & & 3 & 5 & 7 & 9 & 11 \\
\hline Controle & - & - & $1,0 \pm 0,03$ & $2,0 \pm 0,06$ & $3,1 \pm 0,10$ & $4,2 \pm 0,14$ & $5,2 \pm 0,16$ \\
\hline T 1 & Glicerol-3 & 4 & $1,1 \pm 0,06$ & $2,3 \pm 0,07$ & $3,6 \pm 0,14$ & $4,9 \pm 0,20$ & $6,0 \pm 0,26$ \\
\hline Т 2 & 3 & 6 & $1,0 \pm 0,06$ & $2,1 \pm 0,18$ & $3,3 \pm 0,16$ & $4,7 \pm 0,26$ & $5,6 \pm 0,44$ \\
\hline T 3 & 3 & 8 & $1,1 \pm 0,04$ & $2,3 \pm 0,07$ & $3,5 \pm 0,09$ & $4,8 \pm 0,12$ & $5,9 \pm 0,17$ \\
\hline T 4 & 6 & 4 & $1,1 \pm 0,09$ & $2,4 \pm 0,10$ & $3,6 \pm 0,17$ & $4,9 \pm 0,23$ & $6,0 \pm 0,31$ \\
\hline T 5 & 6 & 6 & $1,0 \pm 0,05$ & $1,8 \pm 0,11$ & $2,8 \pm 0,20$ & $3,8 \pm 0,25$ & $4,7 \pm 0,33$ \\
\hline T 6 & 6 & 8 & $1,0 \pm 0,02$ & $2,1 \pm 0,05$ & $3,3 \pm 0,10$ & $4,5 \pm 0,13$ & $5,6 \pm 0,17$ \\
\hline Controle & - & - & $2,65 \pm 0,15$ & $4,71 \pm 0,04$ & $6,21 \pm 0,1$ & $7,6 \pm 0,28$ & $8,7 \pm 0,14$ \\
\hline T 1 & Sorbitol - 4 & 4 & $2,31 \pm 0,08$ & $4,06 \pm 0,21$ & $5,5 \pm 0,28$ & $7,19 \pm 0,03$ & $8,23 \pm 0,23$ \\
\hline Т 2 & 4 & 6 & $2,67 \pm 0,14$ & $4,75 \pm 0,25$ & $6,22 \pm 0,5$ & $7,88 \pm 0,37$ & $8,87 \pm 0,08$ \\
\hline T 3 & 4 & 8 & $2,37 \pm 0,02$ & $4,29 \pm 0,09$ & $5,74 \pm 0,14$ & $7,27 \pm 0,23$ & $8,42 \pm 0,31$ \\
\hline T 4 & 8 & 4 & $2,38 \pm 0,05$ & $4,28 \pm 0,07$ & $5,7 \pm 0,02$ & $7,03 \pm 0,09$ & $8,08 \pm 0,32$ \\
\hline T 5 & 8 & 6 & $2,54 \pm 0,05$ & $4,5 \pm 0,08$ & $6 \pm 0,1$ & $7,49 \pm 0,12$ & $8,64 \pm 0,13$ \\
\hline Т 6 & 8 & 8 & $2,61 \pm 0,14$ & $4,61 \pm 0,01$ & $5,9 \pm 0,32$ & $7,74 \pm 0,14$ & $8,96 \pm 0,32$ \\
\hline
\end{tabular}


As laranjas cobertas com CPSL e glicerol apresentaram-se secas, após 24 horas da aplicação, o que permitiu o manuseio das frutas. Nos tratamentos em que foi utilizado glicerol a 3\%, a cobertura começou a se soltar da casca da laranja a partir do sétimo dia de armazenamento. A descamação da cobertura pode estar relacionada à quantidade insuficiente de glicerol. Thomazine et al. (2005) observaram aumento na flexibilidade de filmes de gelatina, quando se aumentou a concentração de plastificante; esse aumento está relacionado com a adaptabilidade da cobertura ao produto.

Apesar das diferenças significativas entre os tratamentos com glicerol e o tratamento controle, não houve grande diferença numérica entre os valores, o que significa que, em termos práticos, a adição de CPSL associado ao glicerol não impediu a perda de massa das frutas.

No atributo cor da casca da fruta, as análises foram feitas dentro de cada tratamento, durante o período de armazenamento, considerando-se que poderia haver diferenças entre os lotes dos tratamentos. Nas coberturas de CPSL + glicerol, não houve diferença dentro dos tratamentos e do controle, durante todo o período de armazenamento (Figura 1). Essa combinação de proteína e plastificante pode não ter reduzido as trocas gasosas, e assim possibilitou a continuidade da respiração. Conseqüentemente, permitiu a mudança da cor da casca da laranja, a qual está relacionada à conversão

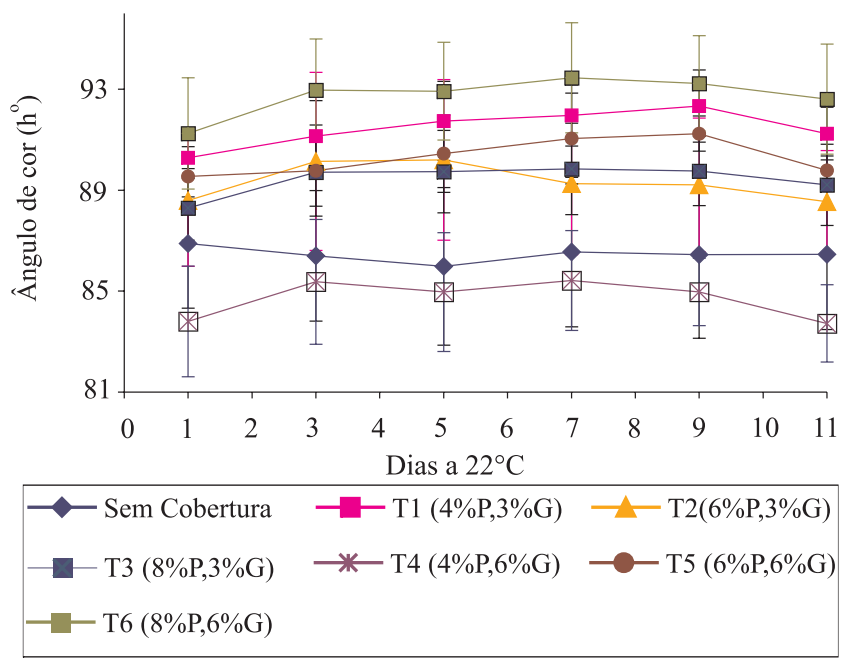

Figura 1. Cor da casca de laranja 'Pera' com coberturas de concentrado protéico de soro de leite e glicerol, em função do tempo de armazenamento ( $\mathrm{P}$ = proteína; $\mathrm{G}$ = glicerol). dos cloroplastos para cromoplastos. Em processos de amadurecimento, a degradação da clorofila e o acúmulo do licopeno ( $\beta$-carotenóide), responsáveis pela cor amarelo-laranja, podem ser lentos em frutos climatéricos. As concentrações de $\beta$-caroteno tendem a mudar muito lentamente, durante o amadurecimento da fruta (Shewfelt, 2003).

No experimento 2, ocorreu interação dupla entre os fatores proteína e sorbitol $(\mathrm{p}<0,01)$. Não houve, porém, interação significativa entre o tempo de armazenamento e as concentrações de proteína e sorbitol. Nas concentrações de 4 e $6 \%$ de proteína, não houve efeito das concentrações de sorbitol na perda de massa dos frutos. Na concentração de $8 \%$ de proteína, a menor perda de peso ocorreu na menor concentração de 3\% (Tabela 1). Essa menor perda pode ter ocorrido em razão da baixa concentração de sorbitol. Thomazine et al. (2005) observaram que o aumento na concentração de plastificante (glicerol e sorbitol), em filmes de gelatina, acarreta aumento na permeabilidade ao vapor d'água.

As soluções filmogênicas com sorbitol, utilizadas para cobrir as laranjas, praticamente não se soltaram das cascas das frutas, durante todo o período de armazenamento. Quando comparadas laranjas que utilizaram coberturas com CPSL e glicerol, e as cobertas com CPSL e sobitol, observou-se que apenas as coberturas com glicerol despregaram da casca da fruta.

$\mathrm{Na}$ análise estatística do atributo cor nas laranjas cobertas com CPSL + sorbitol, ocorreu interação dupla somente entre proteína e sorbitol. Não houve efeito do sorbitol nas concentrações de 4 e 6\% de proteína. Entretanto, a cor verde das laranjas permanecu na concentração de $8 \%$ de proteína e $8 \%$ de sorbitol (Figura 2). Na maior concentração de proteína e de sorbitol, o uso do plastificante provavelmente ocasionou diminuição na troca gasosa, dificultando, conseqüentemente a transformação da clorofila. Por sua vez, as outras combinações podem ter favorecido a troca gasosa e, conseqüentemente, a transformação da clorofila em cromoplastos.

Os tratamentos tiveram efeito discreto nos valores de sólidos solúveis, acidez titulável e rendimento do suco (Tabela 2). No final do experimento, os teores de sólidos solúveis dos frutos recobertos com 4 e com $6 \%$ de proteína e com $3 \%$ de glicerol, bem como aqueles com $8 \%$ de proteína e $6 \%$ de glicerol foram menores que os 
teores dos frutos do grupo controle. Somente frutos que receberam a cobertura com $8 \%$ de sorbitol, combinado com $4 \%$ ou com $6 \%$ de proteína, apresentaram teores de sólidos maiores do que os do grupo controle. Entretanto, apesar de significativas, essas diferenças têm pouco sentido prático, porque os valores estiveram muito próximos (Tabela 2). O mesmo ocorreu com a porcentagem de acidez titulável e com o rendimento de suco, em que os valores numéricos foram muito semelhantes (Tabela 2).

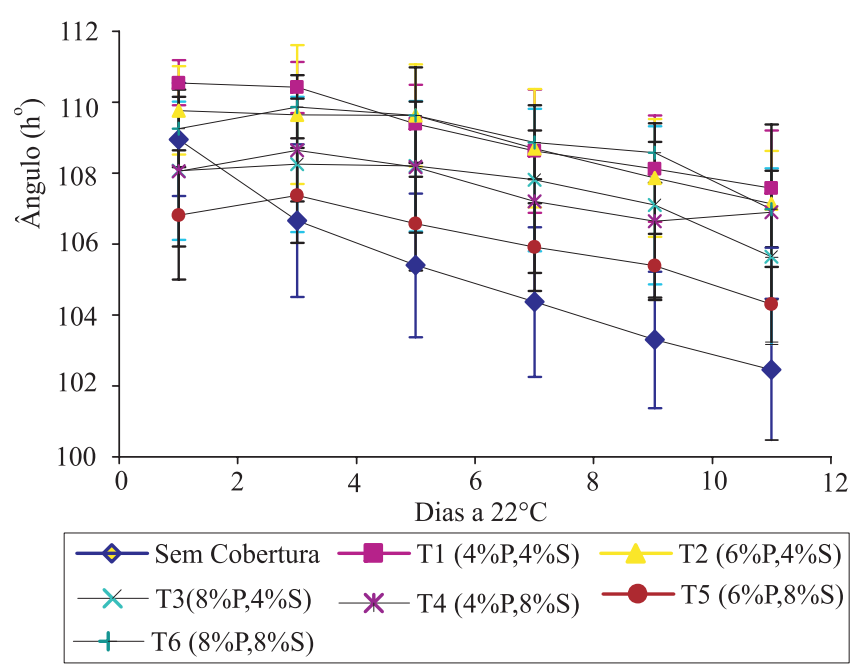

Figura 2. Cor da casca de laranja 'Pera' com coberturas de concentrado protéico de soro de leite e sorbitol, em função do tempo de armazenamento ( $\mathrm{P}=$ proteína; $\mathrm{S}=$ sorbitol).

Tabela 2. Sólidos solúveis, acidez titulável e rendimento do suco de laranja 'Pêra', coberta com concentrado protéico de soro de leite e glicerol (A) e concentrado protéico de soro de leite e sorbitol (B), armazenadas a $22^{\circ} \mathrm{C}$ por 11 dias.

\begin{tabular}{|c|c|c|c|c|c|c|}
\hline \multirow[t]{2}{*}{ Tratamento } & \multicolumn{2}{|c|}{$\begin{array}{l}\text { Sólidos } \\
\text { solúveis } \\
\left({ }^{\circ} \text { Brix }\right) \\
\end{array}$} & \multicolumn{2}{|c|}{$\begin{array}{c}\text { Acidez } \\
\left(\mathrm{mg} \text { ác. cítrico } 100 \mathrm{~g}^{-1}\right) \\
\end{array}$} & \multicolumn{2}{|c|}{$\begin{array}{c}\text { Rendimento } \\
\text { do suco } \\
(\%) \\
\end{array}$} \\
\hline & A & B & A & B & A & $\mathrm{B}$ \\
\hline Controle & $8,85 \mathrm{a}$ & $9,37 \mathrm{c}$ & $0,75 \mathrm{a}$ & $0,96 \mathrm{abc}$ & $51,5 \mathrm{a}$ & $\overline{55,43 b}$ \\
\hline $\mathrm{T} 1$ & $7,76 \mathrm{~b}$ & $9,34 c$ & $0,65 \mathrm{c}$ & $0,98 \mathrm{ab}$ & $47,9 \mathrm{a}$ & $58,77 \mathrm{a}$ \\
\hline $\mathrm{T} 2$ & $7,62 b$ & $9,62 b c$ & $0,66 b c$ & $1,03 \mathrm{a}$ & $50,0 \mathrm{a}$ & $58,72 \mathrm{a}$ \\
\hline T3 & $7,90 \mathrm{ab}$ & $9,65 b c$ & $0,74 \mathrm{a}$ & $0,96 \mathrm{abc}$ & $50,0 \mathrm{a}$ & $58,87 \mathrm{a}$ \\
\hline $\mathrm{T} 4$ & $8,27 \mathrm{ab}$ & $9,81 \mathrm{ab}$ & $0,64 \mathrm{c}$ & $1,01 \mathrm{a}$ & $50,4 \mathrm{a}$ & $60,13 a$ \\
\hline T5 & $8,31 \mathrm{ab}$ & $10,19 \mathrm{a}$ & $0,75 \mathrm{a}$ & $0,91 b c$ & $51,9 \mathrm{a}$ & $58,36 \mathrm{ab}$ \\
\hline T6 & $7,81 \mathrm{~b}$ & $9,42 b c$ & $0,75 \mathrm{a}$ & $0,90 \mathrm{c}$ & $50,9 \mathrm{a}$ & $59,86 \mathrm{a}$ \\
\hline Frutos recém-colhidos & 8,20 & 9,37 & 0,79 & 0,92 & 49,13 & 58,80 \\
\hline DMS 5\% & 0,99 & 0,42 & 0,09 & 0,07 & 4,13 & 3,03 \\
\hline
\end{tabular}

(1) Médias seguidas de letra igual, na coluna, não diferem pelo teste de Tukey a 5\% de probabilidade.

\section{Conclusão}

A redução na perda de matéria fresca e as alterações físico-químicas, proporcionadas pelas diferentes coberturas à base de proteínas, são de pequena magnitude.

\section{Referências}

AGRIANUAL 2003: anuário da agricultura brasileira. São Paulo: FNP Consultoria \& Comércio, 2002. p.295-332.

ALLEONI, A.C.C.; ANTUNES, A.J. Internal quality of eggs with whey protein concentrate. Scientia Agricola, v.61, p.276-280, 2004.

BANKER, G.S. Films coating theory and practice. Journal of Pharmaceutical Sciences, v.55, p.81-89, 1966.

CARVALHO, C.R.L.; MANTOVANI, D.M.B.; CARVALHO, P.R.N.; MORAES, R.M.M. Análises químicas de alimentos. Campinas: Ital, 1990. 121p.

CISNEROS-ZEVALLOS, L.; KROCHTA, J.M. Internal modified atmospheres of coated fresh fruits and vegetables: understanding relative humidity effects. Journal of Food Science, v.67, p.27922797, 2002.

CISNEROS-ZEVALLOS, L.; KROCHTA, J.M. Whey protein coatings for fresh fruits and relative humidity effects. Journal of Food Science, v.68, p.176-181, 2003.

CHO, S.Y.; PARK, J.W.; RHEE, C. Properties of laminated films from whey powder and sodium caseinate mixtures and zein layers. Lebensmittel-Wissenschaft und-Technologie, v.35, p.135-139, 2002.

DONHOWE, G.; FENNEMA, O. Edible films and coatings: characteristics, formation, definitions, and testing methods. In: KROCHTA, J.M.; BALDWIN, E.A.; NISPEROS-CARRIEDO, M.O. (Ed.). Edible coatings and films to improve food quality. Lancaster: Technomic Publ. Co., 1994. p.1-24.

FANG, Y.; TUNG, M.A.; BRITT, I.J.; YADA, S.; DALGLEISH, D.G. Tensile and barrier properties of edible films made from whey proteins. Journal of Food Science, v.67, p.188-193, 2002.

GENNADIOS, A.; McHUGH, T.H.; WELLER, C.L.; KROCHTA, J.M. Edible coatings and films based on proteins. In: KROCHTA, J.M.; BALDWIN, E.A.; NISPEROS-CARRIEDO, M.O. (Ed.). Edible coatings and films to improve food quality. Lancaster: Technomic Publ. Co., 1994. p.201-277.

KROCHTA, J.M. Proteins as raw materials for films and coatings: definitions, current status, and opportunities. In: GENNADIOS, A. (Ed.). Protein-based films and coatings. Boca Raton: CRC Press, 2002. p.1-32.

McHUGH, T.H.; KROCHTA, J.M. Sorbitol vs glycerol plasticized whey protein edible films: integrated oxygen permeability and tensile property evaluation. Journal of Agricultural and Food Chemistry, v.42, p.841-845, 1994. 
MOTA, W.F. da; SALOMÃO, L.C.C.; CECON, P.R.; FINGER, F.L. Waxes and plastic film in relation to the shelf life of yellow passion fruit. Scientia Agricola, v.60, p.51-57, 2003.

PARK, H.J. Development of advanced edible coatings for fruits. Trends in Food Science and Technology, v.10, p.254-260, 1999.

PÈREZ-GAGO, M.B.; KROCHTA, J.M. Water vapor permeability of whey protein emulsion films as affected by $\mathrm{pH}$. Journal of Food Science, v.64, p.695-698, 1999.

SHAW, N.B.; MONAHAN, F.J.; O’RIORDAN, E.D.; O'SULLIVAN, M. Physical properties of WPI films plasticized with glycerol, xylitol, or sorbitol. Journal of Food Science, v.67, p.164-167, 2002.
SHEWFELT, R.L. Color. In: BARTZ, J.A.; BRECHT, J.K. (Ed.). Postharvest physiological and pathology of vegetables. New York: Marcel Dekker, 2003. p.287-296.

TALENS, P.; KROCHTA, J.M. Plasticizing effects of beeswax and carnauba wax on tensile and water vapor permeability properties of whey protein films. Journal of Food Science, v.70, p.239-243, 2005.

THOMAZINE, M.; CARVALHO, R.A.; SOBRAL, P.J.A. Physical properties of gelatin films plasticized by blends of glycerol and sorbitol. Journal of Food Science, v.70, p.172-176, 2005.

WILLS, R.; McGLASSON, B.; GRAHAM, D.; JOYCE, D. Introducción a la fisiología y manipulación poscosecha de frutas, hortalizas y plantas ornamentales. Zaragoza: Acribia, 1998. 240p.

Recebido em 7 de abril de 2005 e aprovado em 19 de julho de 2006 